Journal of Current and Advance Medical Research

January 2019, Vol. 6, No. 1, pp. 59-63

http://www.banglajol.info/index.php/JCAMR

ISSN (Print) 2313-447X

ISSN (Online) 2413-323X

NLM Catalog ID 101673828

DOI: https://doi.org/10.3329/jcamr.v6i1.40787

REVIEW ARTICLE OPEN@ACCESS

\title{
Genetics of Type 2 Diabetes: A Review
}

\author{
Md. Fakruddin \\ Industrial Microbiology Laboratory, Institute of Food Science and Technology (IFST), Bangladesh Council of Scientific and \\ Industrial Research (BCSIR), Dhaka, Bangladesh \& Department of Molecular Physiology, Graduate School of Medical Science, \\ Kumamoto University, Japan
}

\section{Abstract}

Diabetes Mellitus (DM), one of the most non-communicable diseases, is increasing day by day in an alarming way. More than 140 million people are suffering from diabetes throughout the world. It is not a single disease entity, but rather a group of metabolic disorders sharing the common underlying feature of hyperglycemia. Hyperglycemia in diabetes results from defects in insulin secretion, insulin action, or, most commonly, both. The chronic hyperglycemia and attendant metabolic deregulation may be associated with secondary damage in multiple organ systems, especially the kidneys, eyes, nerves, and blood vessels. The pathophysiology of diabetes is not fully elucidated. Insulin secretory dysfunction and insulin resistance or both is main candidate for this metabolic disorder, moreover various genetic and environmental factors may also involve in this process. Racial variations play also an important role as evidenced by various studies. However, the interrelationships between the molecular and metabolic mechanisms in these parameters contributing this life threatening disease still remain a mystery to the scientists. [Journal of Current and Advance Medical Research 2019;6(1):59-63]

Keywords: Diabetes; type 2; genetic; factors; mechanism

Correspondence: Md. Fakruddin, Industrial Microbiology Laboratory, Institute of Food Science and Technology (IFST), Bangladesh Council of Scientific and Industrial research (BCSIR), Dhaka-1205, Bangladesh; Email: fakruddinmurad@gmail.com Cite this article as: Fakruddin M. Genetics of Type 2 Diabetes: A Review. J Curr Adv Med Res 2019;6(1): 59-63

Funding: This study has been performed without any funding from outside else.

Conflict of Interest: There was no conflict of interest to any of the authors.

Contributions to authors: Fakruddin $\mathrm{M}$ has searched and has collected the literature as well as has prepared \& has revised the manuscript.

Copyright: (02019. Fakruddin. Published by Journal of Current and Advance Medical Research. This article is published under the Creative Commons CC BY-NC License (https://creativecommons.org/licenses/by-nc/4.0/). This license permits use, distribution and reproduction in any medium, provided the original work is properly cited, and is not used for commercial purposes.

\section{Introduction}

Diabetes is a chronic disease that occurs either when the pancreas does not produce enough insulin or when the body cannot effectively use the insulin which produces by its own ${ }^{1}$. Diabetes mellitus results from a deficiency in the amount of insulin released from the pancreas in response to glucose (type I) or from a decrease in the ability of muscle and fat cells to respond to insulin (type II) ${ }^{2}$. In both 
types, the regulation of blood glucose is impaired, leading to persistent hyperglycemia and numerous other possible complications in untreated patients ${ }^{3}$. Most of the people in the world with diabetes mellitus have type II; however, the underlying mechanism of this form of the disease is not well understood.

\section{Diabetes Mellitus}

Diabetes mellitus (DM) is not a single disease entity, but rather a group of metabolic disorders sharing the common underlying feature of hyperglycemia ${ }^{4}$. Hyperglycemia in diabetes results from defects in insulin secretion, insulin action, or, most commonly, both. The chronic hyperglycemia and attendant metabolic dysregulation may be associated with secondary damage in multiple organ systems, especially the kidneys, eyes, nerves, and blood vessels ${ }^{5}$. Diabetes is a leading cause of endstage renal disease, adult-onset blindness, and nontraumatic lower extremity amputations worldwide ${ }^{6}$. Worldwide, more than 140 million people suffer from diabetes, making this one of the most common non-communicable diseases ${ }^{7}$. The number of affected individuals with diabetes is expected to double by 2025 . The countries with the largest number of diabetics are India, China, and the United States ${ }^{7}$.

Type 2 diabetes mellitus (T2DM, previously known as non-insulin-dependent diabetes mellitus or NIDDM) is caused by a combination of peripheral resistance to insulin action and an inadequate secretory response by the pancreatic $\beta$-cells ("relative insulin deficiency"). Approximately $80 \%$ to $90 \%$ of patients have type 2 diabetes $^{8}$.

\section{Genetics of type 2 diabetes}

Several studies have found that genetic components play an important role in pathogenesis of type 2 diabetes. Several prospective studies and cross sectional studies have reported that positive family history among first degree relatives confers an increased risk of type 2 diabetes and the risk is greater when both parents are affected ${ }^{9}$. A study on twins has demonstrated that concordance estimate for type 2 diabetes is high in monozygotic compared to dizygotic and the rate increases with duration of follow up. Also, diabetes prevalence varies substantially among different ethnic groups, and this observation of substantial variation of disease prevalence across ethnic groups that share a similar environment, supports the idea that genetic factors contribute to disease predisposition ${ }^{10}$. Data from multiple laboratories support that genetic factors predispose to development of type 2 diabetes by reducing insulin sensitivity and insulin secretion which deteriorate in parallel in most human type 2 diabetes $\operatorname{cases}^{11}$. Curreeent studies have identified variants in 11 genes (TCF7L2, PPARG, FTO, KCNJ11, NOTCH2, WFS1, CDKAL1, IGF2BP2, SLC30A8, JAZF1, and HHEX) to be significantly associated with the risk of type 2 diabetes independently of other clinical risk factors and variants in 8 of these genes were associated with impaired beta-cell function. Among these genes, expressed in pancreatic cells and involved in impairment of insulin secretion, the transcription factors7-like 2 (TCF7L2), is the locus with the highest risk of type 2 diabetes (HR 1.5) ${ }^{12}$. This corresponds to an attributable risk of $25 \%$, due to an average single allele frequency $18-30 \%$ in Northern Europeans. Still the value of genetic information decreased by duration of follow up and eventually only increases the receiver operating characteristics (ROC) achieved by clinical risk factors from 0.74 to $0.75(p<0.0001)$. So far genetic information is of interest for research purposes only ${ }^{13}$.

\section{Role of Genetics in the Development of Diabetes}

T2D is a polygenic, multifactorial disease and the risk for T2D is thought to be influenced by many genes with minor effects together with environmental factors. Until recently, genetics of T2D had limited success with only a few truly verified genes. Until 2007, the dissection of genetic predisposition to T2D was performed by linkage using microsatellites and candidate gene association studies ${ }^{14}$. With GWAS and large meta-analyses several novel T2D genes have finally been identified and verified, the function of which still remains to be elucidated ${ }^{15}$. Many genes have been proposed as candidate genes for T2D but only few susceptibility genes have been convincingly associated in several studies, including PPARG, KCNJ11, TCF7L2 and WFS1. Many other genes have been associated with T2D in some studies but not in others, including IRSI, CAPN10, ADBR3, PPARGC1A, ENPPI and others ${ }^{16}$. Many of these genes have been investigated as candidate genes because of their biological function. Common polymorphisms in MODY genes, such as TCF2,

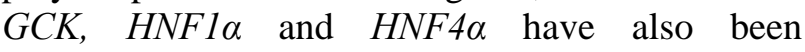
implicated in the development of $\mathrm{T} 2 \mathrm{D}^{17}$.

\section{IRS1}

Insulin receptor substrate 1 (IRS1) is one of the proteins involved in signal transduction of the 
activated insulin receptor by phosphorylation on its tyrosine residues ${ }^{18}$. A common polymorphism G972R (rs1801278), located close to the tyrosine phosphorylation motifs, has been associated with T2D in some but not in all studies ${ }^{19}$. A metaanalysis of 27 studies shows modest association with T2D, but this association could not have been confirmed by current large study or GWAS for T2D. The same polymorphism has also been associated with insulin resistance in obese but not in lean individuals ${ }^{20}$. Also the expression of IRSI mRNA has been reported to be lower in skeletal muscle from insulin resistant non-diabetic subjects. Mice lacking the IRSI display mild insulin resistance and hyperinsulinemia but do not develop diabetes. Tissue specific knock-out experiments indicate a role for IRS1 in insulin signaling in skeletal muscle, adipose tissue and pancreatic $\beta$ cells ${ }^{21}$.

\section{PPARG}

The peroxisome proliferator-activated receptor gamma gene (PPARG) encodes a transcription factor highly expressed in adipose tissue and involved in adipocyte differentiation. $P P A R G$ is also a target of the anti-diabetic, insulin sensitizing drugs thiazolidinediones (TZD) ${ }^{22}$. This gene has been widely studied because it is important in adipocyte and lipid metabolism. In addition, it is a target for the hypoglycemic drugs known as thiazolidinediones ${ }^{23}$. One form of the $P P A R \gamma$ gene (Pro) decreases insulin sensitivity and increases T2D risk by several fold. Perhaps more importantly is that this variant is very common in most populations ${ }^{24}$. Approximately $98 \%$ of Europeans carry at least one copy of the Pro allele. Thus, it likely contributes to a considerable proportion $(\sim 25 \%)$ of $\mathrm{T} 2 \mathrm{D}$ that occurs, particularly among Caucasians ${ }^{25}$. The minor Ala-allele in in PPARG, (Pro12Ala, rs1801282) has been associated with lower BMI, increase in insulin sensitivity and reduced risk of T2D. This association has been confirmed by several recent GWAS for T2D ${ }^{26}$.

\section{KCNJ11}

A common, non-synonymous SNP (E23K, rs5219) in the potassium channel, inwardly rectifying, subfamily J, member $11(K C N J 11)$ has been associated with T2D in several large studies and this finding was confirmed by several recent GWAS $^{27}$. The gene encodes the Kir6.2 subunits of the inwardly rectifying KATP-channel. The KATP channels in pancreatic $\beta$-cells consist of four pore forming Kir6.2 subunits surrounded by four regulatory sulfonylurea receptor 1 (SUR1) subunits and regulate insulin secretion by coupling metabolism to electrical activity ${ }^{28}$. The E23K polymorphism affects ATP sensitivity of the KATP-channel; homozygous KK-genotype carriers show two fold reduced sensitivity to ATP ${ }^{29}$. The KATP-channels are targets for sulfonylureas, drugs used to treat diabetes by closing the channel and triggering insulin secretion. Activating mutations in KCNJ11 are known to cause neonatal diabetes and inactivating mutations neonatal hypoglycemia ${ }^{30}$.

\section{TCF7L2}

The association between polymorphisms in TCF7L2 and T2D was first discovered in 2006 by Grant and colleagues when investigating a region linked to T2D on chromosome $10 \mathrm{q} 25^{31}$. This association did, however, not explain the linkage to this region. The association has thereafter been confirmed by several studies, including all GWAS and TCF $7 L 2$ is therefore considered the strongest susceptibility gene for $\mathrm{T} 2 \mathrm{D}^{32}$. TCF $7 L 2$ encodes a transcription factor involved in the Wnt signaling pathway but the mechanism by which it contributes to the pathogenesis of T2D is poorly understood ${ }^{33}$. Several studies have shown that an intronic SNP in TCF7L2 is associated with impaired insulin secretion and $\beta$-cell function but not insulin action. It has been suggested that the impaired insulin secretion can be mediated by an impaired incretin effect $^{34}$.

\section{WSF1}

WFS1 was identified as a candidate gene for T2D in a study of 83 candidate genes for $\beta$-cell function and T2D. Meta analysis of 11 studies confirmed rs10010131 as a susceptibility variant for T2D with genome-wide significant $\mathrm{p}$-value $(\mathrm{p}=5.4 \times 10-11)^{35}$. WFS1 encodes wolframin, a membrane glycoprotein regulating calcium homeostasis in the endoplasmic reticulum. Mutations in WSF1 cause the Wolfram syndrome, characterized by diabetes insipidus, DM, optic atrophy and deafness ${ }^{36}$.

\section{UABCC8 (ATP binding cassette, subfamily C, member 8) $U$}

This gene encodes the high-affinity sulfonylurea receptor (SUR1) subunit that is coupled to the Kir6.2 subunits (encoded by UKCNJ11U, also known as the potassium channel, inwardly rectifying subfamily $\mathrm{J}$, member 11 ). Both genes are part of the ATP-sensitive potassium channel, which plays a key role in regulating the release of hormones, such as insulin and glucagon, in the beta 
cell $^{37}$. Mutations in either gene can affect the potassium channel's activity and insulin secretion, ultimately leading to the development of T2D. Interestingly, $A B C C 8$ and $K C N J 11$ are only $4.5 \mathrm{~kb}$ apart, and not far from the INS gene. Variant forms of $K C N J 11$ (Lys) and $A B C C 8$ (Ala) genes have been associated with $\mathrm{T} 2 \mathrm{D}$, as well as other diabetesrelated traits ${ }^{38}$.

Because of the close proximity of these genes, current studies are evaluating whether they work in concert with each other, or rather have an independent effect on T2D susceptibility. Since PPAR,$A B C C 8$ and $K C N J 11$ are the targets of drugs used routinely in the treatment of $\mathrm{T} 2 \mathrm{D}$, there are pharmacogenetic implications for maintaining good glycemic control ${ }^{39}$. Response to hypoglycemic therapy may actually be related one's genotype. Thus, genetic testing may not only help determine who is at high risk for developing T2D, but also be useful in guiding treatment regimens for $\mathrm{T} 2 \mathrm{D}^{40}$.

\section{CAPN10 (calpain 10)}

CAPN10 encodes an intracellular calciumdependent cysteine protease that is ubiquitously expressed ${ }^{41}$. A haplotype that was initially linked to T2D included an intronic $A$ to $G$ mutation at position 43, which appears to be involved in CAPN10 transcription.

Two amino acid polymorphisms (Thr504Ala and Phe200Thr) have also been associated with T2D risk. However, it has been suggested that the coding and noncoding polymorphisms do not independently influence T2D risk, but instead contribute to an earlier age at diagnosis ${ }^{42}$. Physiological studies suggest that variations in calpain 10 activity effects insulin secretion, and therefore, susceptibility to T2D. Studies from different ethnic groups indicate that the contribution of this locus to increased T2D risk may be much larger in Mexican-American than Caucasian populations ${ }^{43}$.

\section{Other genes involved in T2D Diabetes}

In recent times, six new gene regions (SLC30A8, $C D K A L 1, C D K N 2 A, I G F 2 B P 2, F T O)$ suspected to be involved in T2D were identified by GWAS ${ }^{44}$. None of these regions contains previously known obvious candidate genes, thereby showing the ability of GWAS to uncover new pathophysiological pathways ${ }^{45}$. Meta-analysis of the three large GWAS for T2D revealed additional six loci (JAZF1, CDC123/CAMK1D, TSPAN8/LGR5,
THADA, ADAMTS9, NOTCH2) with genome wide significant association ${ }^{40}$.

\section{Conclusion}

The pathophysiology of diabetes is not fully elucidated. Insulin secretory dysfunction and insulin resistance or both is main candidate for this metabolic disorder; moreover, various genetic and environmental factors may also involve in this process. Racial variations play also an important role as evidenced by various studies. However, the interrelationships between the molecular and metabolic mechanisms in these parameters contributing this life threatening disease still remain a mystery to the scientists.

\section{References}

1. Cho H, Mu J, Kim JK, Thorvaldsen JL, Chu Q, Crenshaw EB et al. Insulin resistance and a diabetes mellitus-like syndrome in mice lacking the protein kinase Akt2 (PKB beta). Science 2001; 292:1728-1731

2. Al-Mahmood AK, Afrin SF, Hoque N. Metabolic Syndrome and Insulin Resistance: Global Crisis. Bangladesh Journal of Medical Biochemistry 2011; 4(1): 27-31

3. Al-Mahmood AK, Afrin SF, Hoque N. Metabolic Syndrome and Insulin resistance: Etiopathegenesis and influencing factors Bangladesh Journal of Medical Biochemistry 2011; 4(2): 26-31

4. Crandall JP, Knowler WC, Kahn SE, Marrero D, Florez JC, Bray GA, et al. The prevention of type 2 diabetes. Nature Clinical Practice Endocrinology \& Metabolism 2008; 4(7): 382-393

5. DeFronzo RA. Pathogenesis of type 2 diabetes: metabolic and molecular implications for identifying diabetes. Diabetes Review 1997; 5:177-269

6. Saltiel AR. New perspectives into the molecular pathogenesis and treatment of type 2 diabetes. Cell 2001; 104(4): 517-529

7. Wild S, Roglic G, Green A, Sicree R, King H. Global prevalence of diabetes: estimates for the year 2000 and projections for 2030. Diabetes Care 2004; 27: 1047-1053

8. Saini V. Molecular mechanisms of insulin resistance in type 2 diabetes mellitus. World Journal of Diabetes 2010; 1(3): 6875

9. Hu FB, van Dam RM, Liu S. Diet and risk of Type II diabetes: the role of types of fat and carbohydrate. Diabetologia 2001; 44(7):805-817

10. Meigs JB, Cupples LA, Wilson PW. Parental transmission of type 2 diabetes: the Framingham Offspring Study. Diabetes 2000; 49(12):2201-2207

11. Das SK, Elbein SC. The genetic basis of type 2 diabetes. Cell Science 2006; 2:100-131

12. Gerich JE. The genetic basis of type 2 diabetes mellitus: impaired insulin secretion versus impaired insulin sensitivity. Endocrine Reviews 1998; 19(4):491-503

13. Prokopenko I, McCarthy MI, Lindgren CM. Type 2 diabetes: new genes, new understanding. Trends in Genetics 2008; 24(12):613-621

14. Cauchi S, Froguel P. TCF7L2 genetic defect and type 2 diabetes. Current Diabetes Reports 2008; 8(2):149-155

15. Choi K, Kim Y-B. Molecular Mechanism of Insulin Resistance in Obesity and Type 2 Diabetes. The Korean Journal of Internal Medicine 2010; 25(2): 119-129 
16. Deborah MM, Christopher BN. Molecular and metabolic mechanisms of insulin resistance and $\beta$-cell failure in type 2 diabetes. Nature Reviews Molecular Cell Biology 2008; 9: 193 205

17. McAteer JB, Prudente S, Bacci S, Lyon HN, Hirschhorn $\mathrm{JN}$, Trischitta V et al. The ENPP1 K121Q polymorphism is associated with type 2 diabetes in European populations: evidence from an updated meta-analysis in 42,042 subjects. Diabetes 2008; 57: 1125-1130

18. Holmkvist J, Akmgren P, Lyssenko V, Lindgren CM, Eriksson K, Isomaa B et al. Common variants in maturity-onset diabetes of the young genes and future risk of type 2 diabetes. Diabetes 2008; 57: 1738-1744

19. White MF. IRS proteins and the common path to diabetes. The American Journal of Physiology- Endocrinology \& Metabolism 2002; 283: E413-E422

20. Jellema A, Zeegers MP, Feskens EJ, Dagnelie PC, Mensink RP. Gly972Arg variant in the insulin receptor substrate-1 gene and association with Type 2 diabetes: a meta-analysis of 27 studies. Diabetologia 2003; 46: 990-995

21. Zeggini E, Parkinson J, Halford S, Owen KR, Frayling TM, Walker $\mathrm{M}$ et al. Association studies of insulin receptor substrate 1 gene (IRS1) variants in type 2 diabetes samples enriched for family history and early age of onset. Diabetes 2004; 53: 3319-3322

22. Nandi A, Kitamura Y, Kahn CR, Accili D. Mouse models of insulin resistance. Physiological Reviews 2004; 84: 623-647 23. Kersten S, Desvergne B, Wahli W. Roles of PPARs in health and disease. Nature 2000; 405:421-424

24. Petersen KF, Krssak M, Inzucchi S, Cline GW, Dufour S, Shulman G. Mechanism of troglitazoneaction in type 2 diabetes. Diabetes 2000; 49:827-831

25. Steinthorsdottir V, Thorleifsson G, Reynisdottir I, Benediktsson R, Jonsdottir T, Walter GB et al. A variant in CDKAL1 influences insulin response and risk of type 2 diabetes. Nature Genetics 2007; 39: 770-775

26. Zeggini E, Weedon MN, Lindgren CM, Frayling TM, Elliot $\mathrm{KS}$, Lango $\mathrm{H}$ et al. Replication of genome-wide association signals in UK samples reveals risk loci for type 2 diabetes. Science 2007; 316: 1336-1341

27. Sladek R, Rocheleau G, Rung J, Dina C, Shen L, Serre D et al. A genome-wide association study identifies novel risk loci for type 2 diabetes. Nature 2007; 445: 881-885

28. Saxena R, Voight BF, Lyssenko V, Burtt NP, de Bakker PI, Chen $\mathrm{H}$ et al. Genome-wide association analysis identifies loci for type 2 diabetes and triglyceride levels. Science 2007; 316, 1331-1336

29. Koster JC, Marshall BA, Ensor N, Corbett JA, Nichols CG. Targeted overactivity of beta cell K(ATP) channels induces profound neonatal diabetes. Cell 2000; 100: 645-654

30. Schwanstecher C, Meyer U, Schwanstecher M. K(IR)6.2 polymorphism predisposes to type 2 diabetes by inducing overactivity of pancreatic beta-cell ATP-sensitive $\mathrm{K}(+)$ channels. Diabetes 2002; 51: 875-879

31. Gloyn AL, Pearson ER, Antcliff JF, Proks P, Bruining GJ, Slingerland AS et al. Activating mutations in the gene encoding the ATP-sensitive potassium-channel subunit Kir6.2 and permanent neonatal diabetes. New England Journal of Medicine 2004; 350, 1838-1849

32. Lyssenko V, Lupi R, Marchetti P, Guerra SD, OrhoMelander M, Almgren P et al. Mechanisms by which common variants in the TCF7L2 gene increase risk of type 2 diabetes. Journal of Clinical Investigation 2007; 117: 2155-2163
33. Cauchi S, Meyre D, Choquet H, Dina C, Born C, Marre M et al. TCF7L2 variation predicts hyperglycemia incidence in a French general population: the data from an epidemiological study on the Insulin Resistance Syndrome (DESIR) study. Diabetes 2006; 55: 3189-3192

34. Loos RJ, Franks PW, Francis RW, Barroso I, Gribble FM, Savage DB et al. TCF7L2 polymorphisms modulate proinsulin levels and betacell function in a British Europid population. Diabetes 2007; 56: 1943-1947

35. Damcott CM, Pollin TI, Reinhart LJ, Ott SH, Shen H, Silver KD et al. Polymorphisms in the transcription factor 7like 2 (TCF7L2) gene are associated with type 2 diabetes in the Amish: replication and evidence for a role in both insulin secretion and insulin resistance. Diabetes 2006; 55: 2654-2659 36. Sandhu MS, Weedon MN, Fawcett KA, Wasson J, Debenham SL, Daly A et al. Common variants in WFS1 confer risk of type 2 diabetes. Nature Genetics 2007; 39: 951-953

37. Strom TM, Hortnagel K, Hofmann S, Gekeler F, Scharfe C, Rabl W et al. Diabetes insipidus, diabetes mellitus, optic atrophy and deafness (DIDMOAD) caused by mutations in a novel gene (wolframin) coding for a predicted transmembrane protein. Human Molecular Genetics 1998; 7: 2021-2028

38. Barroso I, Luan J, Middelberg RPS, Harding A-H, Franks $\mathrm{PW}$, Jakes RW et al. Candidate gene association study in type 2 diabetes indicates a role for genes involved in B-Cell function as well as insulin action. PLoS Biology 2003; 1: 41-55

39. Florez JC, Jablonski KA, Kahn SE, Franks PW, Dabelea D, Hamman RF, et al. Type 2 diabetes-associated missense polymorphisms KCNJ11 E23K and ABCC8A1369S influence progression to diabetes \& response to interventions in the diabetes prevention program. Diabetes 2007; 56(2): 531-536 40. Sakamoto Y, Inoue H, Keshavarz P, Miyawaki K, Yamaguchi Y, Moritani M, et al. SNPs in the KCNJ11-ABCC8 gene locus are associated with type-2 diabetes \& blood pressure levels in the Japanese population. Journal of Human Genetics 2007; 52: 781-793

41. Gloyn AL. The search for type 2 diabetes genes. Ageing Research Reviews 2003; 2: 111-127

42. Cox NJ, Hayes MG, Roe CA, Tsuchiya T, Bell GI. Linkage of calpain 10 to type 2 diabetes: the biological rationale. Diabetes 2004; 53: S19-S25

43. Jensen DP, Urhammer SA, Eiberg H, Borch-Johnsen K, Jorgensen T, Hansen T, et al. Variation in CAPN10 in relation to type 2 diabetes, obesity \& quantitative metabolic traits: studies in 6018 whites. Molecular Genetics \& Metabolism 2006; 89(4): 360-367

44. Horikawa Y, Oda N, Cox NJ, Li X, Orho-Melander M, Hara $\mathrm{M}$ et al. Genetic variation in the gene encoding calpain-10 is associated with type 2 diabetes mellitus. Nature Genetics 2000; 26: 163-175

45. Scott LJ, Mohlke KL, Bonnycasle LL, Willer CJ, Li Y, Duren WL, Erdos MR et al. A genome-wide association study of type 2 diabetes in Finns detects multiple susceptibility variants. Science 2007; 316: 1341-1345

46. Zeggini E, Scott LJ, Saxena R, Voight BF, Marchini JL, Hu $\mathrm{T}$ et al. Meta-analysis of genome-wide association data and large-scale replication identifies additional susceptibility loci for type 2 diabetes. Nature Genetics 2008; 40: 638-645 